\title{
SPATIO-TEMPORAL VARIATION OF PM 2.5 CONCENTRATION IN CHINA FROM 1998 TO 2016 AND ITS RESPONSE TO ECONOMIC DEVELOPMENT
}

\author{
Huizi Zhang ${ }^{1}$, Jianjun Chen ${ }^{1 *}$, Xuning Zhao ${ }^{1}$, Jia Liu ${ }^{1}$ \\ ${ }^{1}$ College of Geomatics and Geoinformation, Guilin University of Technology, No. 12 Jian'gan Road, Guilin, Guangxi,China. \\ 448028541@qq.com; chenjj@glut.edu.cn; zhaoxnyl@163.com
}

KEY WORDS:PM ${ }_{2.5}$, Spatio-temporal variation, Economic development, Response characteristics,MATLAB

\begin{abstract}
:
China's economy has experienced rapid development in the past few decades, and economic development has also brought serious pollution problems, which has attracted wide attention of scholars at home and abroad. Based on the data of global $\mathrm{PM}_{2.5}$ remote sensing products and China's economic development from 1998 to 2016, the temporal and spatial variations of $\mathrm{PM}_{2.5}$ concentration in China from 1998 to 2016 were analyzed, and the response of $\mathrm{PM}_{2.5}$ concentration in China to economic development was studied. The results showed that the average annual $\mathrm{PM}_{2.5}$ concentration in 1998-2016 showed the spatial distribution characteristics of high in the East and low in the west; during 1998-2016, $\mathrm{PM}_{2.5}$ increased significantly in most regions, but decreased significantly in Inner Mongolia, Shaanxi, Ningxia and Gansu, while $\mathrm{PM}_{2.5}$ did not change significantly in some parts of the central region; during 1998-2007, $\mathrm{PM}_{2.5}$ concentration in most regions of China experienced rapid economic development. The concentration of $\mathrm{PM}_{2.5}$ in a few areas such as Inner Mongolia decreased significantly, while that in Yunnan, Sichuan and Inner Mongolia did not change significantly. During the 10 years of economic slowdown in China (2008-2016), the downward trend of $\mathrm{PM}_{2.5}$ concentration in China was expanding. The concentration of $\mathrm{PM}_{2.5}$ in the central and southern regions decreased or did not change significantly, except in the northwest and a few northeast regions. The change of $\mathrm{PM}_{2.5}$ concentration responds obviously to economic development, but the response of different regional economic development to the change of $\mathrm{PM}_{2.5}$ concentration is different.
\end{abstract}

\section{INTRODUCTION}

In recent years, the problem of air pollution caused by China's rapid economic development has attracted extensive attention from all walks of life. In particular, fine particulate matter $\mathrm{PM}_{2.5}$ has great influence on atmospheric visibility and air quality (Lin et al, 2016), and high concentration $\mathrm{PM}_{2.5}$ is also the main cause of smog (Liu et al, 2014;Huang et al,2014; Zhao et al,2013). In addition, it poses a great threat to human health (Wang et al,2012;Han et al,2014;Zhang et $\mathrm{al}, 2014)$. Since the aerodynamic diameter is less than $2.5 \mu \mathrm{m}$, $\mathrm{PM}_{2.5}$ can stay in the air for a long time and adhere to harmful substances. Prolonged exposure to $\mathrm{PM}_{2.5}$ will lead to human health problems and even increase human mortality (Bell et al,2007;Pope et al,2002; Chen et al,2013). In 2013, the International Cancer Research Institute has listed $\mathrm{PM}_{2.5}$ as a human carcinogen (Yang et al,2015; Chun et al,2010). Therefore, a better and clearer understanding of the temporal and spatial changes of $\mathrm{PM}_{2.5}$ is the basis for studying the impact of air pollution and is also helpful to take effective measures against air pollution (Bin et al, 2019).

Currently, there are mainly two ways to obtain $\mathrm{PM}_{2.5}$ concentration data: ground monitoring and remote sensing inversion. Traditional ground monitoring methods include air sample analysis and automatic monitoring by station instruments. This method can obtain high-precision local $\mathrm{PM}_{2.5}$ pollution data, but due to the limitation of its coverage, there is no way to reflect the $\mathrm{PM}_{2.5}$ pollution situation in the whole region (Wang, 2016). However, remote sensing inversion has just made up for this defect. The most widely used method is to use satellite remote sensing atmospheric aerosol optical thickness (AOD) data to retrieve the $\mathrm{PM}_{2.5}$ concentration on the ground (Zhang et al, 2005). At present, the commonly used inversion methods include: dark pixel method, structural function method and Gao Fancha surface method (Li et al, 2012). Dark pixel method is used to retrieve aerosol optical thickness over dense vegetation. For example, Pennina et al. used dark pixel method to retrieve aerosol optical thickness

\footnotetext{
${ }^{*}$ Corresponding author
} 
(Peng et al, 2008). The structural function method uses dry and clean aerosol information as the background, and obtains the aerosol optical thickness on the pollution day from the change of the projection function. For example, Zhu Lin and the like use the structural function method to retrieve the pixel interval setting in the aerosol optical thickness (Zhu et al, 2016). The Gao Fancha surface method is used to retrieve the aerosol optical thickness of two regions with relatively close spatial positions and stable atmospheric optical characteristics. For example, Sun Lin used Gao Fancha surface method to retrieve the aerosol particle spectrum (Sun, 2006).

Since satellite remote sensing inversion can retrieve the distribution characteristics of $\mathrm{PM}_{2.5}$ concentration in the whole region, based on the global annual average $\mathrm{PM}_{2.5}$ remote sensing product data and China's economic development data from 1998 to 2016, this study uses trend analysis and significance test methods to study the temporal and spatial variation characteristics of $\mathrm{PM}_{2.5}$ concentration in China and preliminarily discusses its response to economic development.

\section{MATERIALS AND METHODS}

\subsection{Survey of Research Area}

China is located in the east of Asia and the west coast of the Pacific Ocean. The territory is vast and the total area is about 9.6 million square kilometers. China's terrain is high in the West and low in the east, with a stepped distribution. Mountainous and plateau areas are vast. The distance between the East and the west is about 5000 kilometers, and the coastline of the mainland is more than 18,000 kilometers long. The combination of temperature and precipitation is varied, forming a variety of climates. A total of 34 provincial administrative units, including 23 provinces, 5 autonomous regions, 4 municipalities directly under the Central Government and 2 Special Administrative Regions.

\subsection{Data Sources}

\subsection{1 $\mathrm{PM}_{2.5}$ remote sensing product data}

The remote sensing data used in this paper come from the Social Economic Data and Application Center (SEDAC), the annual global $\mathrm{PM}_{2.5}$ grid (AOD) and gwr from modis, misr and seafis from 1998 to 2016, including the annual concentration $\left(\mathrm{g} / \mathrm{m}^{3}\right)$ of ground fine particles $\left(\mathrm{PM}_{2.5}\right)$, and dust and sea salt are removed. The data set combines AOD retrieval from several satellite instruments, including NASA Moderate Resolution Imaging Spectroradiometer (MODIS), Multi-Angle Imaging Spectroradiometer (MISR) and Sea Vision Wide Field Sensor (SEAFS). Each file contains floating point values that estimate the concentration of $\mathrm{PM}_{2.5}$. The grid resolution of the grid is 0.01 degrees, covering the global land surface, from 70 degrees north latitude to 55 degrees south latitude. The individual files in the following table are compressed GeoTIFF files, with sizes of about 90 to $100 \mathrm{MB}$.

\subsubsection{China's Economic Development Data}

China's Economic and Social Development Statistics Database (CNKI) contains 708 kinds of authoritative statistical data that have been published and distributed since the founding of the People's Republic of China. Among them, there are more than 150 kinds of statistical yearbooks that are still continuously published, covering various fields such as national economic accounting, investment in fixed assets, population and human resources, and is the largest aggregate database of official statistical data in China. This paper uses the data of China's GDP and GDP growth rate from 1998 to 2016 in this database.

\subsection{Research Methods}

In this study, the downloaded aerosol optical thickness product data are preprocessed in ARCGIS software. Firstly, the $\mathrm{PM}_{2.5}$ concentration data in China are cropped according to the boundary vector frame of the study area. Then, the average concentration data map from 1998 to 2016 is synthesized and the raster data map of the subsequent linear regression and significance analysis is derived. The spatial distribution characteristics of $\mathrm{PM}_{2.5}$ concentration changes from 1998 to 2016 in China were realized by MATLAB programming. the method used was linear regression, and the change trend was analyzed by significance test $(\mathrm{P}<0.05)$. The $\mathrm{PM}_{2.5}$ concentration data of each grid point from 1998 to 2016 are simulated as a linear function, and the concentration fluctuation of the corresponding grid point is obtained through the positive and negative values of the slope.

\section{RESULTS AND DISCUSSION}

3.1 Spatial Distribution Characteristics of $\mathbf{P M}_{2.5}$ in China 
In order to comprehensively reflect the spatial distribution characteristics of $\mathrm{PM}_{2.5}$ concentration in China, the data of $\mathrm{PM}_{2.5}$ concentration from 1998 to 2016 were averaged (Figure $1)$, and the spatial distribution data of $\mathrm{PM}_{2.5}$ concentration in China were obtained. The results show that the average concentration of $\mathrm{PM}_{2.5}$ in China from 1998 to 2016 shows the spatial distribution characteristics of high concentration in the middle and east, low concentration in the west, low concentration in the north and slightly high concentration in the south. The highest and lowest concentrations of $\mathrm{PM}_{2.5}$ were $91.9737 \mu \mathrm{g} / \mathrm{m}^{3}$ and $1.5263 \mu \mathrm{g} / \mathrm{m}^{3}$, respectively, distributed in Hebei and Qinghai provinces. The concentration of $\mathrm{PM}_{2.5}$ in economically developed areas is significantly higher than that in areas with lower economic development, especially in economically developed Jiangsu, Shandong, Henan and Hebei provinces, which is significantly higher than that in other areas, indicating that its economic development has a certain impact on the concentration change of $\mathrm{PM}_{2.5}$, but it does not exclude the climatic and topographic reasons, as well as the energy consumption during heating period and the pollution caused by coal combustion. However, the low concentration of $\mathrm{PM}_{2.5}$ in Qinghai Province and Tibet Autonomous Region may be mainly due to the relatively backward economy and the continued low GDP data.

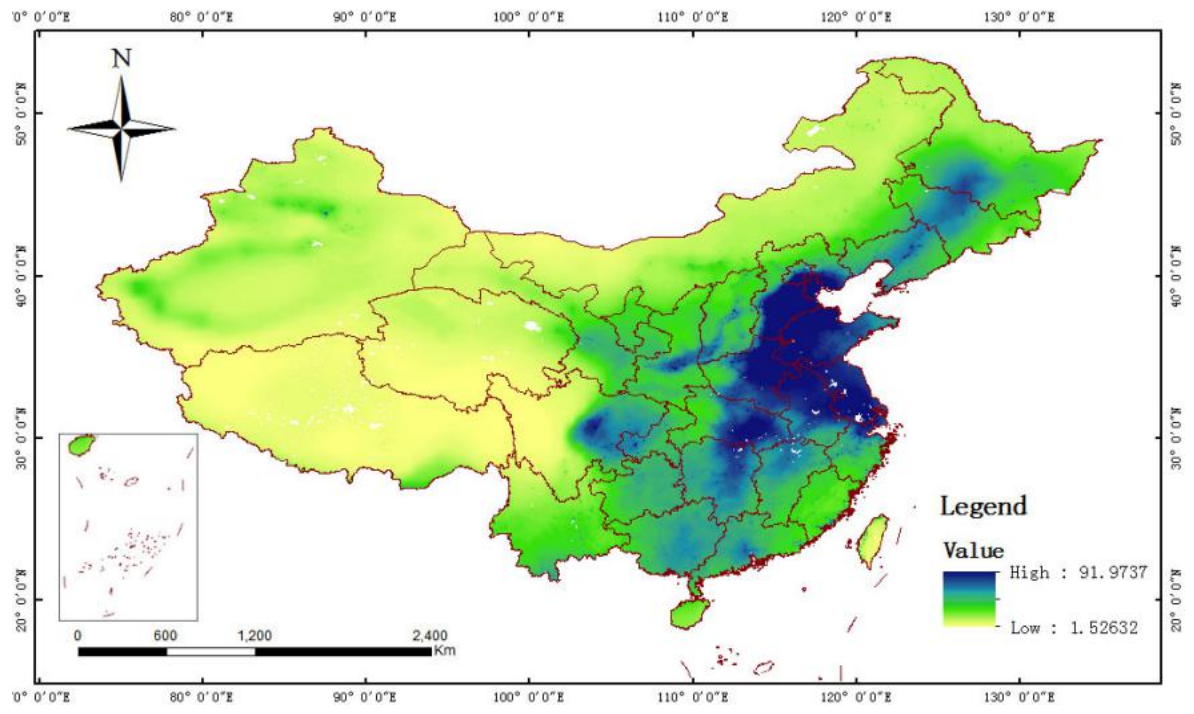

Figure 1. Average Concentration Map of $\mathrm{PM}_{2.5}$ in China from 1998 to 2016

\subsection{Temporal and Spatial Variation Characteristics of $\mathbf{P M}_{2.5}$}

\section{in China}

Using MATLAB software to program, the concentration data of $\mathrm{PM}_{2.5}$ from 1998 to 2016 were analyzed by linear regression fitting, and the slope values obtained were written back into the matrix of each point. As shown in Figure 2, the concentration of $\mathrm{PM}_{2.5}$ in China generally shows a trend of decreasing in the west and increasing in the east. The place with the highest slope was in Hebei Province, with a value of 2.99965 , while the place with the lowest slope was in Shanxi Province, with a value of -1.41544 .

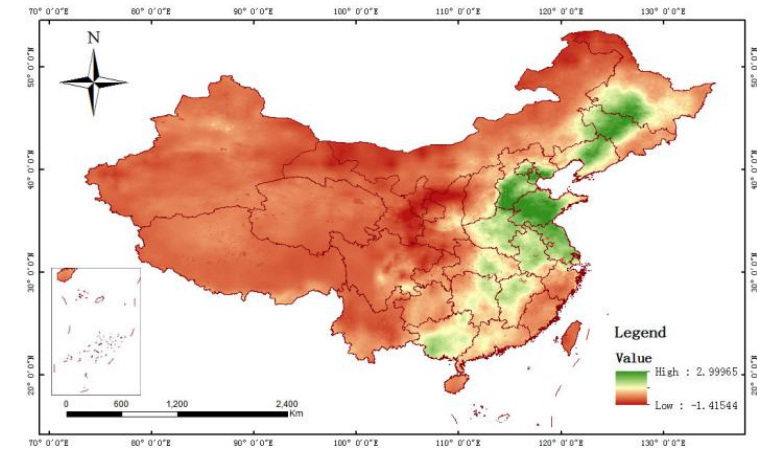

Figure 2. Slope Map of $\mathrm{PM}_{2.5}$ Concentration in China from 1998 to 2016

According to the slope value and through MATLAB, the concentration data of $\mathrm{PM}_{2.5}$ from 1998 to 2016 are subjected to one-dimensional linear regression analysis and significance analysis. the pixel points with slope greater than 0 (i.e. a $>0$ ) and significance level less than 0.05 (i.e. $\mathrm{p}<0.05$ ) are marked as 1 and marked with green. The pixel points with slope less than 
0 (i.e. $\mathrm{a}<0$ ) and significance level less than 0.05 (i.e. $\mathrm{p}<0.05$ ) are marked with red. Pixel points with significance level greater than 0.05 (i.e., $p>=0.05$ ) and pixel points with slope equal to 0 (i.e., $\mathrm{a}=0$ ) and significance level less than 0.05 (i.e., $\mathrm{p}<0.05$ ) are marked with yellow (Figure 3).

From 1998 to 2016, $\mathrm{PM}_{2.5}$ increased significantly in most areas of China, with only some areas such as northwestern Inner Mongolia, northern and southern Gansu, northern Shaanxi and southern Ningxia Hui Autonomous Region showing significant decreases, while $\mathrm{PM}_{2.5}$ did not change significantly in some areas of southwest, northwest, north and east China and Taiwan.

$\mathrm{PM}_{2.5}$ in a city is not only related to economy, but also positively related to population size, temperature, quantity of air pollutants and emissions from nearby cities, and negatively related to precipitation and wind speed (Han et al, 2016). The increasing concentration of $\mathrm{PM}_{2.5}$ in North China and Northeast China may be related to climate factors such as less precipitation and frequent occurrence of dust weather in most areas of North China. However, the southwest region has a lot of rainfall and relatively dense vegetation, so the change is not significant. The significant increase in $\mathrm{PM}_{2.5}$ concentration in eastern, southern and central China may be due to the rapid development of local economy. In areas with serious $\mathrm{PM}_{2.5}$ problems, heavy industry is often the mainstay of their economy and an important source of local government revenue (Cheng et al, 2013).

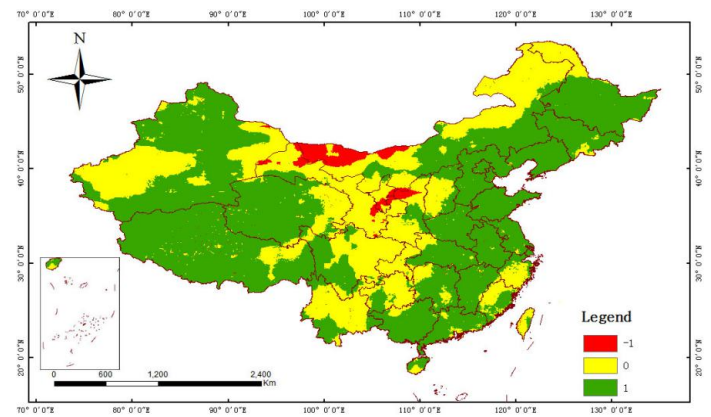

Figure 3. Spatial Variation Map of $\mathrm{PM}_{2.5}$ Concentration in China from 1998 to 2016

\subsection{China's PM $\mathbf{P}_{2.5}$ Response to Economic Development}

The results of Figure 2 and Figure 3 show that the spatio-temporal change characteristics of $\mathrm{PM}_{2.5}$ concentration have obvious response to economic development, but the response of economic development in different regions to the change of $\mathrm{PM}_{2.5}$ concentration has certain differences. The statistical results of China's GDP growth rate from 1998 to 2016 show that China's GDP growth rate rose rapidly from 1998 to 2007, but after 2007, China's GDP growth rate declined obviously, and 2007 was obviously a turning point of China's GDP growth rate. The annual average concentration of $\mathrm{PM}_{2.5}$ in China (Figure 5) has a good correlation with China's economic growth rate (Figure 4). The fastest change rate of China's GDP occurred in 2007, and the average concentration of $\mathrm{PM}_{2.5}$ in that year was also the highest. In order to better analyze the response of China's $\mathrm{PM}_{2.5}$ to economic development, the research period is divided into two sections, namely 1998-2007 (Figure 6) and 2008-2016 (Figure 7).

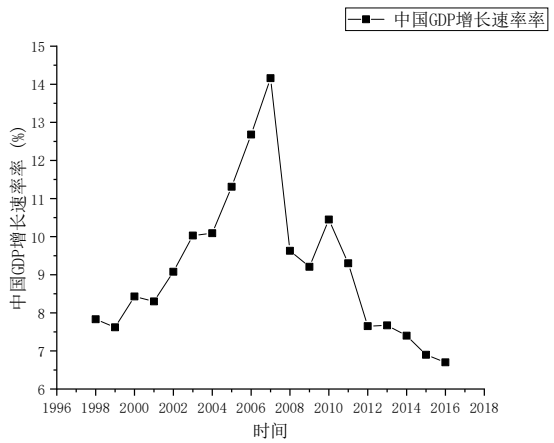

Figure 4. China's GDP Growth Rate 1998-2016

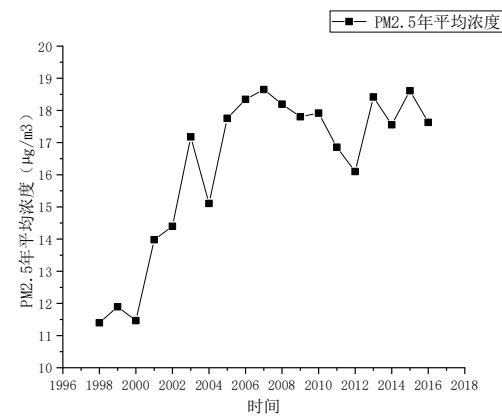

Figure 5. $\mathrm{PM}_{2.5}$ Year Average Concentration Chart

As shown in Figure 6, during the period of 1998-2007 when China's economy was developing rapidly, the concentration of $\mathrm{PM}_{2.5}$ increased significantly in most areas, while the concentration of $\mathrm{PM}_{2.5}$ decreased significantly in only a small part of Inner Mongolia Autonomous Region, Gansu, Xinjiang Uygur Autonomous Region and Tibet Autonomous Region, while there was no significant change in some areas such as Yunnan, Sichuan, Heilongjiang, Jilin, Xinjiang Uygur Autonomous Region, Tibet Autonomous Region and Inner Mongolia Autonomous Region. Among them, pollution in central, southern and eastern China is more serious, indicating that the rapid economic development has had a certain impact on $\mathrm{PM}_{2.5}$. 
According to the line chart of China's GDP growth rate from 1998 to 2016, there was a turning point in 2007. From 1998 to 2007, China's GDP value increased rapidly and the GDP growth rate rose by leaps and bounds. The rapid economic growth has led to the deterioration of the environment. A large number of trees have been cut down. Sewage emissions have led to an increase in the greenhouse effect and the concentration of $\mathrm{PM}_{2.5}$ has continuously increased (Büntgen et al, 2019). The rapid growth of extensive economic in Hebei region is accompanied by huge energy consumption, exhaust emissions caused by the sharp increase in car ownership, and the inflow of air pollutants in surrounding areas such as Shandong Province and Shanxi Province, etc. All these combined factors have significantly increased the concentration of $\mathrm{PM}_{2.5}$ in Beijing-Tianjin-Hebei region (Luo et al, 2018). The concentration of $\mathrm{PM}_{2.5}$ in China's heavy industry base and the three northeast provinces, which are the main grain producing areas, is also increasing due to the industrial structure of heavy industry with high input, high energy consumption and high pollution. Eastern and southern China have experienced $\mathrm{PM}_{2.5}$ pollution problem while their economy is growing rapidly and urbanization is accelerating. $\mathrm{PM}_{2.5}$ mainly comes from automobile exhaust emission and biomass combustion (Hua et al, 2015). In addition, the impact of climate on $\mathrm{PM}_{2.5}$ pollution cannot be ignored. Coastal areas are affected by subtropical monsoon climate, and the transmission and interaction of air pollutants between regions often occur (Xiao et al, 2017). For example, the sustained and stable climate conditions in parts of southwest China have kept the $\mathrm{PM}_{2.5}$ concentration in a relatively stable state.

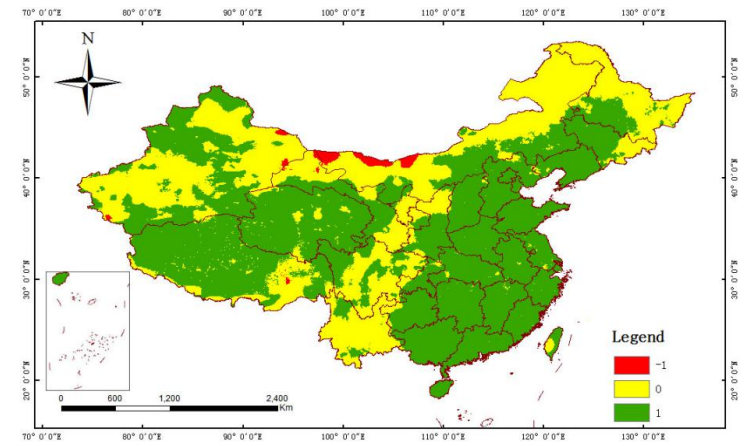

Figure 6. Spatial Variation Map of $\mathrm{PM}_{2.5}$ Concentration in

China from 1998 to 2007

During the 10 years of China's economic slowdown (2008-2016) (Figure 7), the downward trend of $\mathrm{PM}_{2.5}$ concentration in China has been continuously expanding. Although there is no obvious change in most areas, $\mathrm{PM}_{2.5}$ concentration in parts of southwest, central, east and south China has decreased significantly, while $\mathrm{PM}_{2.5}$ concentration in only a small part of northeast, northwest and southwest regions has increased significantly. According to the line chart of China's GDP growth rate from 1998 to 2016, the GDP value began to rise slowly after 2008, and the rate of change of China's GDP growth also began to slow down, while the concentration of $\mathrm{PM}_{2.5}$ began to decline during this period, indicating that the economic slowdown eased the influence of the earlier rapid economic development on the concentration of $\mathrm{PM}_{2.5}$.

The concentration of $\mathrm{PM}_{2.5}$ has changed since 2008. With the slowing down of the development of the top ten high-energy consuming industries, the green development strategy has been advancing steadily, and the energy conservation and consumption reduction effects have been obvious. The concentration of $\mathrm{PM}_{2.5}$ in China has been continuously decreasing (Energy, 2019). Many places in our country (such as Beijing, Shanxi, etc.) have restricted the use of single and double numbers of motor vehicles since the Olympics, and have also effectively controlled a large amount of vehicle exhaust emissions (Fan et al, 2015). At the same time, the natural environment has a negative correlation effect on $\mathrm{PM}_{2.5}$, and precipitation is also one of the reasons for the reduction of $\mathrm{PM}_{2.5}$ concentration. Influenced by precipitation and typhoons, $\mathrm{PM}_{2.5}$ concentrations in parts of southwest, south, central and east China dropped sharply (Dong et al, 2016). In addition, after 2008, people began to realize the importance of protecting the environment. At the same time of economic development, the environment is also one of the wealth that cannot be ignored. After experiencing serious and continuous haze events in many regions of our country, the state Council issued the "air pollution prevention and control action plan" and adopted continuous air pollution measures, the $\mathrm{PM}_{2.5}$ concentration began to slowly slow down (Xinhua News Agency, 2013). Air pollution in most parts of China has improved and $\mathrm{PM}_{2.5}$ concentration has dropped significantly, which indicates that measures related to environmental protection have been successful 


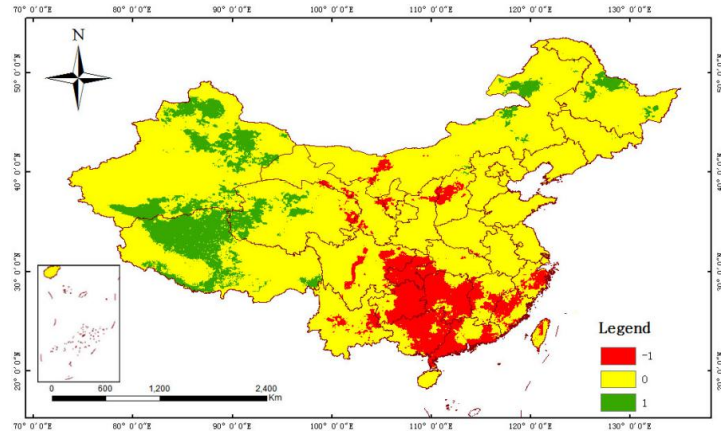

Figure 7. Spatial Variation Map of $\mathrm{PM}_{2.5}$ Concentration in

China from 2008 to 2016

\section{CONCLUSION}

Based on the global average annual $\mathrm{PM}_{2.5}$ remote sensing product data from 1998 to 2016 and the data of China's economic development, this paper analyzes the spatio-temporal changes of $\mathrm{PM}_{2.5}$ in China and its response to economic development. The results show that:

The average concentration of $\mathrm{PM}_{2.5}$ in China shows the spatial distribution characteristics of high in the middle and east, low in the west, low in the north and slightly high in the south, with the highest average value of $91.9737 \mu \mathrm{m} / \mathrm{m}^{3}$ in Hebei Province and the lowest average value of $1.5263 \mu \mathrm{m} / \mathrm{m}^{3}$; in Qinghai Province. From 1998 to 2016, PM $_{2.5}$ increased significantly in most areas of China, with only some areas such as northwestern Inner Mongolia, northern and southern Gansu, northern Shaanxi and southern Ningxia Hui Autonomous Region showing significant decreases, while there was no significant change in $\mathrm{PM}_{2.5}$ in southwest, northwest, northern and eastern China and Taiwan. During the period of 1998-2007 when the economy was developing rapidly, China's GDP increased by leaps and bounds and the growth rate kept rising, which led to the continuous rise of $\mathrm{PM}_{2.5}$ concentration. However, the environmental impacts caused by different economic development in different regions also have certain differences. During the period of 2008-2016 when the economy is slowing down, the downward trend of $\mathrm{PM}_{2.5}$ concentration in China is continuously expanding. Although there is no obvious change in most areas, $\mathrm{PM}_{2.5}$ concentration in parts of southwest, central, east and south China is significantly reduced, while $\mathrm{PM}_{2.5}$ concentration in only a small part of northeast, northwest and southwest regions is significantly increased. The slowing down of the economic development rate indicates that people have realized the impact of rapid economic development on the environment and the importance of environmental protection.
At the same time, the government's measures to curb $\mathrm{PM}_{2.5}$ have also played a good role in environmental governance.

\section{ACKNOWLEDGEMENTS}

This study was supported by the National Natural Science Foundation of China (41801030, 41901370, 41961065); Guangxi Natural Science Foundation (2018GXNSFBA281054, 2018GXNSFBA281075，2017GXNSFDA198016); Research Foundation of Guilin University of Technology (GUTQDJJ2017069); the BaGuiScholars program of the provincial government of Guangxi (Guoqing Zhou).

\section{REFERENCES}

Bell, M. L., Dominici, F., Ebisu, K., Zeger, S. L., Samet, J. M., 2007:Spatial and temporal variation in $\mathrm{PM}_{2.5}$ chemical composition in the United States for health effects studies. Environ. Health Perspect. 115:989-995.

Bin, C., Ling, J., Wang, L., 2019: Spatial and Temporal Variations of $\mathrm{PM}_{2.5}$ in North Carolina. Aerosol and Air Quality Research. 19: 698-710.

Büntgen Ulf, Krusic Paul J, Piermattei Alma, Coomes David A, Esper Jan, Myglan Vladimir S,Kirdyanov Alexander V, Camarero J Julio,Crivellaro Alan, Körner Christian. 2019:Author Correction: Limited capacity of tree growth to mitigate the global greenhouse effect under predicted warming. Nature communications. 10(1).

Chen, Z., Wang, J. N., Ma, G. X., Zhang, Y. S., 2013:China tackles the health effects of air pollution. Lancet .382:1959-1960.

Cheng, Y., Liu, L., Ren, J. 1., 2013:Study on Eco-environmental Effects in the Process of Economic Transition . Contemporary Economic Management. 35(01):19-23.

Chun, C., Bin, Z., 2010. Review of relationship between indoor and outdoor particles: $\mathrm{I} / \mathrm{O}$ ratio, infiltration factor and penetration factor. Atmospheric Environment. 45(2),

Dong, Q., Zhao, P. S., Chen, Y. N.,2016: Impact Clearance Capacity of Rainfall on Aerosol Particles with Different Particle Sizes. Environmental Science. 37(10):3686-3692.

Energy, 2019. Studies from Sun Yat Sen University Reveal New Findings on Energy (Impacts of Energy Consumption Structure, Energy Intensity, Economic Growth, Urbanization On $\mathrm{PM}_{2.5}$ Concentrations In Countries Globally). Energy Weekly News. 
Fan, S. B., Tian, L. D., Zhang, D. X., Qu, S.,2015: Study on Motor Vehicle Emission Factors in Beijing. Environmental Science. 36(07):2374-2380.

Han, L. J., Zhou, W. Q., Li, W. F., 2016:Fine particulate $\left(\mathrm{PM}_{2.5}\right)$ dynamics during rapid urbanization in Beijing, 1973-2013. Scientific Reports. 603-604.

Han, L. J., Zhou, W. Q., Li, W. F., Li, L., 2014;Impact of urbanization level on urban air quality: A case of fine particles $\left(\mathrm{PM}_{2.5}\right)$ in Chinese cities. Environ. Pollut. 194:163-170.

Hua, Y., Cheng, Z., Wang, S. X., 2015:Characteristics and source apportionment of $\mathrm{PM}_{2.5}$ during a fall heavy haze episode in the Yangtze River Delta of China. Atmospheric Environment. 123: 380-391

Huang, R. J., Zhang, Y., Bozzetti, C., Ho, K. F., Cao, J. J., Han, Y., Daellenbach, K. R., Slowik, J. G., Platt, S. M., Canonaco, F., 2014:High secondary aerosol contribution to particulate pollution during haze events in China. Nature. 514:218-222.

Li, J. H., Liu, H. F., Zhao, D. T.,2012: Aerosol Optical Depth Retrieval Algorithm Based on MODIS and Its Application Progress. Green Science and Technology. 02:108-111.

Lin, Y., Ye, Z. X., Yang, H. J., Zhang, J., Yin, W. W., Li, X. F., 2016:Pollution Level and Source Analysis of Atmospheric $\mathrm{PM}_{2.5}$ in Spring in Southwest Suburb of Chengdu. Environmental Science. 37(05):1629-1638.

Liu, Y. J., Zhang, T. T., Liu, Q. Y., Zhang, R. J., Sun, Z. Q., Zhang, M. G., 2014:Seasonal variation of physical and chemical properties in TSP $\mathrm{PM}_{10}$ and $\mathrm{PM}_{2.5}$ at a roadside site in Beijing and their influence on atmospheric visibility. Aerosol Air Qual. Res.14:954-969.

Luo, Y., Deng,Q. F., Kun, y., Yang, Y., Shang, C. X., Yu, Z. Y., 2018:Temporal and spatial evolution of $\mathrm{PM}_{2.5}$ in typical regions of China in the past 20 years. Environmental Science. 39(07):3003-30.

Peng, N., Yi, W. N., Fang, Y. H.,2008: Dark Pixel Method for Retrieving Aerosol Optical Thickness in $400 \sim 1000$ nm Band. Infrared and Laser Engineering. 05:878-883.

Pope, C. A., Burnett, R. T., Thun, M. J., Calle, E. E., Krewski, D., Ito, K., Thurston, G. D., 2002:Lung cancer,cardiopulmonary mortality, and long-term exposure to fine particulate air pollution. JAMA. J. 287:1132-1141.

Sun, L.,2006. Retrieval of Atmospheric Aerosol from Remote Sensing in Urban Areas. Graduate School of Chinese Academy of Sciences (Institute of Remote Sensing Applications).

Wang, S., Hao, J., 2012:Air quality management in China:
Issues, challenges, and options. J. Environ. Sci. 24:2-13.

Wang, X.,2016. Study on Remote Sensing Inversion Method of $\mathrm{PM}_{2.5}$ Concentration in Beijing-Tianjin-Hebei Region. Hebei Normal University.

Xiao, H., Huang, Z. W., Zhang, J. J., 2017: Identifying the impacts of climate on the regional transport of haze pollution and inter-cities correspondence within the Yangtze River Delta. Environmental Pollution. 228: 26-34.

Xinhua News Agency. 2013.State Council Releases "Air Pollution Prevention Action Plan". Paper Information. (12):58-58.

Yang, Y. X., Bin, Z., Lin, Z., Rong, L., 2015:Spatiotemporal variations of $\mathrm{PM}_{2.5}$ and $\mathrm{PM}_{10}$ concentrations between 31 Chinese cities and their relationships with $\mathrm{SO}_{2}, \mathrm{NO}_{2}, \mathrm{CO}$ and $\mathrm{O}_{3}$. Particuology. 20(03):141-149.

Zhang, F., Cheng, H. R., Wang, Z. W., Lv, X. P., Zhu, Z. M., Zhang, G., Wang, X. M ,2014; Fine particles $\left(\mathrm{PM}_{2.5}\right)$ at a CAWNET background site in Central China: Chemical compositions, seasonal variations and regional pollution events. Atmos. Environ. 86:193-202.

Zhang, Y., Pun, B.,Wu, S. Y.,Vijayaraghavan, K., Seigneur, C.,2005: Application and evaluation of two air quality models for particulate matter for a southeastern U.S. episode. Air \& Waste Management Association. Journal. 54(12).

Zhao, X., Zhao, P., Xu, J.,Meng, W., Pu, W., Dong, F., He, D.,Shi, Q., 2013; Analysis of a winter regional haze event and its formation mechanism in the North China Plain. Atmos. Chem. Phys. 13:5685-5696.

Zhu, L., Sun, L., Yang, L., Xu, F. F., Qing, S. X.,2016: Interval Setting of Pixel in Inversion of Aerosol Optical Thickness by Structural Function Method . Journal of Remote Sensing. 20(04):528-539. 